\title{
Risk of Major Adverse Cardiovascular Events in Patients With Rheumatoid Arthritis
}

Kheraj Mal ${ }^{1}$, Ratan Kumar ${ }^{2}$, Farah Mansoor ${ }^{3}$, Navneet Kaur ${ }^{4}$, Anil Kumar ${ }^{1}$, Sidra Memon ${ }^{3}$, Amber Rizwan ${ }^{5}$

1. Cardiology, National Institute of Cardiovascular Diseases, Sukkur, PAK 2. Cardiology, Khairpur Medical College, Nawabshah, PAK 3. Internal Medicine, Jinnah Sindh Medical University, Karachi, PAK 4. Internal Medicine, Adesh Institute of Medical Sciences and Research, Buchu Kalan, IND 5. Family Medicine, Jinnah Post Graduate Medical Center, Karachi, PAK

Corresponding author: Amber Rizwan, amber_aljazeera109@hotmail.com

\section{Abstract}

\section{Introduction}

Rheumatoid arthritis is a chronic, inflammatory, and multisystem disease, which, along with the joints, can involve the cardiovascular system. The treatment of rheumatoid arthritis or rheumatoid arthritis itself can lead to atherosclerosis, which is considered one of the major causes by which it can affect the cardiovascular system. In this study, we will assess the risk of cardiovascular events in patients with rheumatoid arthritis as compared to the general population.

\section{Method}

This case-control study was conducted from January 2018 to November 2018. Two-hundred twenty-two (222) patients with diagnosed rheumatoid arthritis were included as cases in the study. Two-hundred eleven (211) patients were included in the study as the control group (patients without rheumatoid arthritis). All the data were recorded in a self-structured questionnaire.

\section{Result}

Participants with rheumatoid arthritis also showed an increased risk of myocardial infarction (MI) by an odds ratio of 2.50 ( $95 \% \mathrm{CI}$; 0.77-8.14). There was also an increased risk of cardiovascular death in participants with rheumatoid arthritis by an odds ratio of 1.99 (0.58-6.71).

\section{Conclusion}

The study suggests that rheumatoid arthritis along with joint inflammation can also affect the cardiovascular system. Hence, a multidisciplinary team of rheumatologists and cardiologists should manage patients suffering from rheumatoid arthritis, which will improve morbidity and mortality in such patients.

Review began 12/13/2020 Review ended 12/17/2020 Published 12/23/2020

\section{(๑) Copyright 2020}

Mal et al. This is an open access article distributed under the terms of the Creative Commons Attribution License CC-BY 4.0., which permits unrestricted use, distribution, and reproduction in any medium, provided the original author and source are credited.
Categories: Cardiology, Rheumatology

Keywords: rheumatoid arthritis, myocardial infarction, cardiovascular events, autoimmune diseases

\section{Introduction}

Rheumatoid arthritis (RA) is an autoimmune disorder affecting multiple parts of the body. It is more common in females than in males [1]. This disease can involve multiple systems other than joints due to systemic inflammation, including the cardiovascular system [2]. RA speeds up atherosclerosis in the vessels, leading to an increased risk of myocardial infarction (MI) and stroke. These can cause high mortality among patients suffering from RA [3]. The overall incidence of cardiovascular events among RA patients is relatively more common as compared to the general public, thus making RA an independent risk factor for cardiovascular diseases like diabetes mellitus [4-6].

Various risk factors and mechanisms are identified to explain the increased risk of cardiovascular events in patients with rheumatoid arthritis. These mechanisms include undertreatment of cardiovascular risk factors in RA patients, adverse events associated with the treatment of RA, and the inflammatory process in RA, which leads to accelerated atherosclerosis [7].

Currently, to the best of our knowledge, there is no study based in Pakistan assessing cardiovascular risk in patients with rheumatoid arthritis. More insight and local data are required to assist clinicians in discussing the management of cardiovascular risk in patients with RA.

\section{Materials And Methods}




\section{Cureus}

This case-control study was conducted in a tertiary-care hospital in Pakistan. Two-hundred twenty-two (222) patients with a confirmed diagnosis of rheumatoid arthritis were included in the study from January 2018 to November 2018, with the help of rheumatologists. Two-hundred eleven (211) participants, matched for age and gender with the case group, without a known diagnosis of rheumatoid arthritis, were included from the outpatient department of cardiology unit as the control group.

All participants' age, body mass index, hypertension status, smoking status, gender, and physical activity were noted in a self-structured questionnaire. Physical inactivity included patient responses 'no exercise' or 'one to two times a month' versus 'regular exercise one or more times a week'. Their blood was drawn and sent to the laboratory for cholesterol levels.

Patients were followed for 12 months or for the development of a major cardiovascular event (MACE), whichever came first. In this study, MACE was defined as patients having a nonfatal stroke, nonfatal myocardial infarction, and cardiovascular death. Two-hundred ten (210) participants from the case group completed the study while two-hundred five (205) participants from the control group completed the study. Only participants who completed the study were included in the final analysis.

Statistical analysis was done using the Statistical Package for the Social Sciences (SPSS) v. 23.0 (IBM Corp., Armonk, NY). Continuous variables were analyzed via descriptive statistics and were presented as mean data while standard deviations (SDs) were presented as categorical data. The t-test and chi-square were applied as appropriate. The odds ratio was calculated to measure the association between RA and cardiovascular events. A p-value of less than 0.05 meant that the difference between the groups is significant and the null hypothesis is void.

\section{Results}

The characteristics and risk factor profile were similar between both groups, except that physical inactivity was significantly more common in participants with rheumatoid arthritis ( -value $<0.00001$ ) (Table 1 ).

\begin{tabular}{|c|c|c|c|}
\hline Characteristics & $\begin{array}{l}\text { Participants with Rheumatoid Arthritis } \\
\text { (n=210) }\end{array}$ & $\begin{array}{l}\text { Participants without Rheumatoid Arthritis } \\
\text { ( } \mathrm{n}=205)\end{array}$ & p-value \\
\hline Age in years (Mean $\pm S D$ ) & $46 \pm 12$ & $48 \pm 13$ & NS \\
\hline Male \% & 42 & 49 & NS \\
\hline BMI greater than $25 \mathrm{~kg} / \mathrm{m}^{2}(\%)$ & 33 & 31 & NS \\
\hline $\begin{array}{l}\text { Cholesterol level greater than } 200 \\
\mathrm{mg} / \mathrm{dL}\end{array}$ & 32 & 35 & NS \\
\hline Hypertensive (\%) & 32 & 35 & NS \\
\hline Current smokers (\%) & 17 & 19 & NS \\
\hline Physically inactive (\%) & 76 & 48 & $\begin{array}{l}< \\
0.00001\end{array}$ \\
\hline \multicolumn{4}{|c|}{ TABLE 1: Comparison of participants with rheumatoid arthritis vs. participants without } \\
\hline & 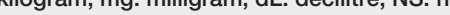 & 和 & \\
\hline
\end{tabular}

Participants with rheumatoid arthritis had an increased risk of myocardial infarction by an odds ratio of 2.50 (95\% CI; 0.77-8.14). There was also an increased risk of cardiovascular death in participants with rheumatoid arthritis by an odds ratio of 1.99 (0.58-6.71) (Table 2). 
effects, such as hypertension, weight gain, and impaired glucose tolerance, which are all modifiable risk factors for MI [22-23]. Other pharmacotherapy for RA includes tumor necrosis factor (TNF) alpha inhibitors, methotrexate, and hydroxychloroquine, which have been shown to reduce the likelihood of MI [13,24].

MI is one of the major causes of premature death in patients suffering from RA. Some studies have found an equal risk of increase of MI in patients with RA in comparison with diabetic patients [25]. Lowering systemic inflammation, assessing RA markers as an early sign of CVD, prescribing cardioprotective medication for RA treatment, and encouraging patients to increase physical activity will prove to be beneficial in reducing the risk and mortality rate due to $\mathrm{MI}$ in patients with RA. It is, therefore, essential to consider RA as an independent risk factor for CVD.

\section{Conclusions}

Rheumatoid arthritis is a chronic debilitating condition affecting a variety of organ systems, especially affecting the blood vessels, leading to increased mortality due to myocardial infarction. Hence, to prevent such grave complications, rheumatologists and cardiologists should work together to screen the patients already suffering from rheumatoid arthritis for a possibility of impending myocardial infarction. Diagnostic and management plans should be devised to control such outcomes, which will help in improving the morbidity and mortality of these patients.

\section{Additional Information \\ Disclosures}

Human subjects: Consent was obtained by all participants in this study. Khairpur Medical College issued approval KMC/2018/IRB-Off-19. Animal subjects: All authors have confirmed that this study did not involve animal subjects or tissue. Conflicts of interest: In compliance with the ICMJE uniform disclosure form, all authors declare the following: Payment/services info: All authors have declared that no financial support was received from any organization for the submitted work. Financial relationships: All authors have declared that they have no financial relationships at present or within the previous three years with any organizations that might have an interest in the submitted work. Other relationships: All authors have declared that there are no other relationships or activities that could appear to have influenced the submitted work.

\section{References}

1. Scott DL, Wolfe F, Huizinga TW: Rheumatoid arthritis. Lancet. 2010, 376:1094-1108. 10.1016/S01406736(10)60826-4

2. Sandoo A, Zanten J, Metsios GS, Carroll D, Kitas GD: Vascular function and morphology in rheumatoid arthritis: a systematic review. Rheumatology. 2011, 50:2125-2139. 10.1093/rheumatology/ker275

3. Kaplan MJ: Cardiovascular disease in rheumatoid arthritis . Curr Opin Rheumatol. 2006, 18:289-297. 10.1097/01.bor.0000218951.65601.bf

4. Bacon PA, Stevens RJ, Carruthers DM, Young SP, Kitas GD: Accelerated atherogenesis in autoimmune rheumatic diseases. Autoimmun Rev. 2002, 1:338-347. 10.1016/S1568-9972(02)00100-3

5. del Rincón ID, Williams K, Stern MP, Freeman GL, Escalante A: High incidence of cardiovascular events in a rheumatoid arthritis cohort not explained by traditional cardiac risk factors. Arthritis Rheum. 2001, 44:2737-2745.

6. Solomon DH, Goodson NJ, Katz JN, et al.: Patterns of cardiovascular risk in rheumatoid arthritis . Ann Rheum Dis. 2006, 65:1608-1612. 10.1136/ard.2005.050377

7. Lindhardsen J, Ahlehoff O, Gislason GH, Madsen OR, Olesen JB, Torp-Pedersen C, Hansen PR: The risk of myocardial infarction in rheumatoid arthritis and diabetes mellitus: a Danish nationwide cohort study. Ann Rheum Dis. 2011, 70:929-934. 10.1136/ard.2010.143396

8. Naranjo A, Sokka T, Descalzo MA, et al.: Cardiovascular disease in patients with rheumatoid arthritis: results from the QUEST-RA study. Arthritis Res Ther. 2008, 10:R30. 10.1186/ar2383

9. Meune C, Touzé E, Trinquart L, Allanore Y: Trends in cardiovascular mortality in patients with rheumatoid arthritis over 50 years: a systematic review and meta-analysis of cohort studies. Rheumatology (Oxford). 2009, 48:1309-1313. 10.1093/rheumatology/kep252

10. Smolen JS, Aletaha D, McInnes IB: Rheumatoid arthritis. Lancet. 2016, 22:2023-2038. 10.1016/S01406736(16)30173-8

11. Karpouzas G, Ahmadi N, Choi T: Lower prevalence and severity of 'vulnerable' coronary plaque in a-TNFexposed asymptomatic patients with rheumatoid arthritis. Arthritis Rheum. 2010,

12. Charles-Schoeman C, Lee YY, Grijalva V, et al.: Cholesterol efflux by high density lipoproteins is impaired in patients with active rheumatoid arthritis. Ann Rheum Dis. 2012, 71:1157-1162. 10.1136/annrheumdis-2011200493

13. Charles-Schoeman C: Cardiovascular disease and rheumatoid arthritis: an update . Curr Rheumatol Rep. 2012, 14:455-462. 10.1007/s11926-012-0271-5

14. Schaftenaar F, Frodermann V, Kuiper J, Lutgens E: Atherosclerosis: the interplay between lipids and immune cells. Curr Opin Lipidol. 2016, 27:209-215. 10.1097/MOL.0000000000000302

15. Incalza MA, D'Oria R, Natalicchio A, Laviola L, Giorgino F: Oxidative stress and reactive oxygen species in endothelial dysfunction associated with cardiovascular and metabolic diseases. Vascul Pharmacol. 2018, 100:1-19. 10.1016/j.vph.2017.05.005

16. Sidibé A, Mannic T, Arboleas M, et al.: Soluble VE-cadherin in rheumatoid arthritis patients correlates with 


\section{Cureus}

disease activity: evidence for tumor necrosis factor $\alpha$-induced VE-cadherin cleavage. Arthritis Rheum. 2012, 64:77-87. 10.1002/art.33336

17. Hjeltnes G, Hollan I, Førre Ø, Wiik A, Mikkelsen K, Agewall A: Anti-CCP and RF IgM: predictors of impaired endothelial function in rheumatoid arthritis patients. Scand J Rheumatol. 2011, 40:422-427.

10.3109/03009742.2011.585350

18. Giles JT, Post WS, Blumenthal RS, et al.: Longitudinal predictors of progression of carotid atherosclerosis in rheumatoid arthritis. Arthritis Rheum. 2011, 63:3216-3225. 10.1002/art.30542

19. Ricci NA, Cunha AIL: Physical exercise for frailty and cardiovascular diseases . Adv Exp Med Biol. 2020, 1216:115-129. 10.1007/978-3-030-33330-0_12

20. Verhoeven F, Tordi N, Prati C, Mougin F, Wendling D: Physical activity in patients with rheumatoid arthritis. Joint Bone Spine. 2016, 83:265-270. 10.1016/j.jbspin.2015.10.002

21. Myers J, Kokkinos P, Nyelin E: Physical activity, cardiorespiratory fitness, and the metabolic syndrome . Nutrients. 2019, 11:1652. 10.3390/nu11071652

22. Krasselt M, Baerwald C: Efficacy and safety of modified-release prednisone in patients with rheumatoid arthritis. Drug Des Devel Ther. 2016, 10:1047-1058. 10.2147/DDDT.S87792

23. Boateng S, Sanborn T: Acute myocardial infarction. Dis Mon. 2013, 59:83-96. 10.1016/j.disamonth.2012.12.004

24. Rempenault C, Combe B, Barnetche T, Gaujoux-Viala C, Lukas C, Morel J, Hua C: Metabolic and cardiovascular benefits of hydroxychloroquine in patients with rheumatoid arthritis: a systematic review and meta-analysis. Ann Rheum Dis. 2018, 77:98-103. 10.1136/annrheumdis-2017-211836

25. Ráček V, Němec P: Rheumatoid arthritis - an independent risk factor for cardiovascular disease [Article in Czech]. Vnitr Lek. 2012, 58:834-838. 